\title{
Study on Flipped Classroom Teaching Mode Based on Learning Space in WorldUC
}

\author{
Lijuan Ye, Jiaming Zhong ${ }^{\text {a }}$ \\ Xiangnan University, 423000 Chenzhou Hunan, China
}

\begin{abstract}
The learning space in worldUC is an effective way to construct a web-based, digital, personal, and life-long educational system, as well as to bring forth new educational teaching modes. Therefore, this paper introduces the construction and function of learning space in worldUC, and analyzes the connotation, targets, as well as meaning of flipped classroom. Meanwhile, it puts forward the implementation, basic principles, and strategies for flipped classroom, and proposes suggestions for flipped classroom, to provide references for flipped classroom.
\end{abstract}

\section{Introduction}

Modern teaching space has been expanded gradually due to fast promotion of applications and rapid development of modern information technology, such as new generation internet, cloud computing, internet of things, new generation mobile communication, and computerbased multimedia. Therefore, information technology that centers on network technology has been widely applied in teaching, and it has become one of the main teaching ways in the 21 century.

American Maureen Age, Glenn Platt and Michael Regalia introduced the "flipped teaching" mode that they adopted to teach "Introduction to Economics" in University of Miami in 2000, as well as their achievements. However, they did not come up with "flipped classroom" or "flipped teaching". In 2007, Jonathan Bergmann and Aaron Sims, chemistry teachers in Colorado Woodland Park High School, adopted "flipped classroom" teaching mode in their class, and promoted this mode to American primary schools and middle schools. With the development and popularization of internet, flipped classroom is being gradually popular in America. At present, flipped classroom has received widespread application in America, and with outstanding effect. Nevertheless, the research and practice about flipped classroom in China is still at the early stage.

\section{Connotation and Meaning of Flipped Classrooms}

\subsection{Connotation of Flipped Classrooms}

According to a series of domestic and foreign researches on flipped classrooms, the definition of flipped classrooms can be roughly summarized as follows: flipped classroom is putting the stages of knowledge imparting and knowledge internalization during the learning process upside down. That is to say, students can impart the knowledge by watching teaching videos before class and internalize the knowledge through all kinds of teaching ways in class, such as group discussion, school assignments, and personal tutoring from teachers.

\subsection{Meaning of Flipped Classrooms}

\subsubsection{Promoting the Implementation of personal Teaching}

Before classes, teachers and students will transmit the videos as knowledge carrier, and examine learning effect through exercises, to realize independent learning and personal learning. Then, students can adopt the most suitable methods and progress to develop learning, to enhance their learning efficiency and effect greatly, as well as to train learners' independent learning ability. Through assignments, flipped classroom will deepen students' understanding about knowledge, and promote their preliminary internalization about knowledge.

\subsubsection{Promoting the Overall Improvement of Students' Comprehensive Quality}

In classes, teachers will help students carry out in-depth communication and expand their knowledge by making use of cooperation, inquiring, discussion, and other methods. The activities like group discussion can promote the interaction between teachers and students, as well as between students. Through solving problems together, this method will improve students' cognitive levels, and train their abilities like exchanging, communication, cooperation, and inquiring. Besides, it can transfer the "teacher-centered" teaching mode to the

a Corresponding author: jmzhongcn@163.com 
new teaching mode of "focusing on teaching and learning", thus enhancing students' comprehensive quality in an all-around way.

\section{FUNCTIONS OF NETWORK E- LEARNING SPACE IN WORLDUC}

\subsection{Construction of Network e-Learning Space}

Network e-learning space is made up of personal space and organizational space, which also integrates data analysis and public application service. It supports users with different roles (e.g.: administrators,students,parents, teachers) to exchange their identities in the same space, to come true "one space for one person". It also supports the users with different roles to interaction, to come true data exchange and information communication. What's more, it supports the transferring and converging of all sorts of public application services, to come true knowledge sharing.

\subsection{Basic Functions of personal Space}

personal space includes the space for teachers, students, parents, or administrators. The personal space can transfer all kinds of public application services, featuring the following basic functions: personal management, Information management, Resource management, Application management, Community management.

\subsection{Functions about the Role of Teachers}

Based on the basic functions of personal space, teachers' space should also provide the following functions: Teaching Management, Student Analysis, Network Research.

\subsection{Functions about the Role of Students}

Based on the basic functions of personal space, students' space should also provide the following functions: Learning Management, Learning Feedback, Growth Record.

\subsection{Functions about the Role of Parents}

Based on the basic functions of personal space, parent space should also provide the following functions: Inquiry of Learning, Family-School Interaction.

\subsection{Functions about the Role of Administrators}

Administrators consist of school managers and regional managers. However, based on the basic functions of personal space, administrators should also provide the following functions:

Inquiry the Situation of Running a School, Inquiry Space Applications.

\subsection{Basic Functions of organizational Space}

organizational space includes area space, school space, and class space, which can transfer various public application services, supporting generative resource management, information releasing, member management, as well as activity organization and analysis.

\section{IMPLEMENTATION OF FLIPPED CLASSROOM AND ITS BASIC PRINCIPLES}

In order to realize flipped classroom, it requires teachers to implement teaching activities in the information environment based on multi-media and network, and make the course teaching contents as learners' learning resources after processing the information. Meanwhile, these learning resources should be provided for learners to share learning, but not only for the demonstration of teachers. We should also ask students to reconstruct knowledge by making use of information processing tools, reorganize and create the course contents by utilizing digital tools for word processing, image processing, and information integration. Therefore, flipped classroom can not only impart knowledge to students, but also help students acquire knowledge, and make students reconstruct and create knowledge.

\subsection{Level of Schools}

From the perspective of a school, it should undergo the following eight basic processes to achieve favorable effect of flipped classroom.

First, a digital hardware environment should be constructed, because hardware environment offers material conditions for integration, such as the construction of digital classroom, digital office, and digital campus. When preparing hardware devices, we should emphasize the importance of teaching, and have priority in making the devices closely related to teaching.

Second, all kinds of application software platforms for teaching should be established. The role of hardware depends on the application software platforms relating to all kinds of school businesses, including teaching platform, resource platform, management platform, and communication platform.

Third, educational and teaching software resource library should be established. Software only offers tools to deal with teaching or management issues, and it must have processing objects to possess real value, so we must establish educational resources matching the software, such as teaching resources supporting teaching platform, and management information resources supporting the management platform.

Fourth, teachers' flipped classroom should also be trained. The key of integration is the teacher. Without active participation of teachers, integration will be nonsense. Therefore, we need to train teachers from the following four levels: training of advanced educational theory in modern information environment, to change 
traditional teaching concepts. First of all, schools should train teachers' information technology ability, so that they can express teaching contents and teaching methods, or optimize teaching structure by making use of technologies. Then, teachers' way to design their teaching should be trained, so that they can design a perfect teaching plan. What's more, the mode of flipped classroom should be trained, with the aim of helping teachers understand the concrete process and methods for information teaching.

\subsection{Level of Teachers}

Teachers should clearly understand and master the following principles in teaching practice. Based on this, teachers can create various kinds of integrating methods and modes to reflect the course features and reflect personal teaching styles.

\subsubsection{Guided by Advanced Educational Thinking, Teaching and learning Theory (Constructivism Theory in Particular)}

The key of flipped classroom is to change traditional teaching structure and educational concept radically, to train a large batch of innovative talents. Flipped classroom must regard advanced theories as guidance. Making use of constructivism as guidance is especially targeted for the current status of educational field in China---it emphasizes "students centered" feature, and asks students to construct the meaning of constructivism independently.

\subsubsection{Integrate by Surrounding the Creation of "New Teaching Structure"}

To achieve flipped classroom, except advanced theoretical guidance, we should strive to create a new teaching structure (it is called the teaching structure "focusing on teaching and learning") that can both give full play to the guiding role of teachers and fully embody the dominant role as students. The creation surrounding the "new teaching structure" requires teachers to pay close attention to the position and function of four factors (teachers, students, teaching contents, and teaching media) in teaching environment during the teaching design of course integration: can we change the position and function of each factor during the "integration" process when compared with traditional teaching process? How big is the changing degree? Which factors will change? Are there any other factors to be changed? Which factors are not changing? What are the reasons? Only if we analyze the issue around these questions and make corresponding adjustment, can we reflect the requirements of this new teaching structure through the teaching model of the final teaching design. This is the significance of integration.

\subsubsection{Make Teaching Design for Course Integration by Applying the Theory of "Focusing on Teaching and Learning"}

At present, popular theories about teaching design mainly consist of the teaching design "focusing on teaching" and "focusing on learning". However, because these two theories have their own advantages and disadvantages, the most ideal method is to combine them together, complement each other, and form a teaching design theory "focusing on learning and teaching" to complement each other.

\section{CONCLUSIONS}

Flipped classroom teaching can meet students' needs of personalized learning, and help students acquire guidance and help in an independent and convenient way. Meanwhile, teachers will have more energy to design their teaching, master and guide students' study, or obtain more targeted measures to organize classroom teaching, thus enhancing teaching quality. In order to apply flipped classroom teaching to practice in a better way, we still need to make continuous exploration, summary, and research, to continuously consummate each link of flipped classroom teaching in sustainable teaching practice, and push forward teaching reform. With the deepening of educational information, flipped classroom based on network learning space will offer new thinking for the teaching and learning in information age.

\section{Acknowledgement}

Thanks for being supported by Hunan Provincial Natural Science Foundation of China(No.2018JJ2371), 2013 Hunan Province Colleges and universities teaching reform research project (based on cyberspace "management information system" inquiry teaching research and practice), Hunan provincial colleges and universities in the 13th five-year plan comprehensive reform pilot program(Xiang jiantong [2016] 276-82).

\section{References}

1. M.J. Lage, G.J.Platt, M.Treglia, Journal of Economic Education, 31,1(2000)

2. Z.L. Wu, L. Zhao, China Educational Technology, 4(2014)

3. J.L. Zhang, China Remote Education, 10(2013)

4. S.Q. Guo, B. Yang, China Educational Technology, 4(2014)

5. K.K. He, E-Education Research, 4(2004)

6. S.Q. $\mathrm{Yu}, \mathrm{J} . \mathrm{Wu}$, Information technology and curriculum integration teaching mode and method in the network age (Shanghai Education Press, 2005)

7. Y.L. Zheng, L.Y. Li, Y.N. Wang, Modern Remote Education, 3(2010) 
8. Ministry of Education of the People's Republic of China,

http://www.moe.gov.cn/srcsite/A16/s3342/201805/t 20180502_334758.html

9. S.Q. Yu, Q.L. Lu, S.J. Chen, China University Teaching, 10(2005)

10. K.K.He,

http://www.edu.cn/20031126/3094951.shtml

11. Q. Lu, E-education Research, 8(2013) 